\title{
Intraductal tubulopapillary neoplasms of the bile ducts: clinicopathologic, immunohistochemical, and molecular analysis of 20 cases
}

Anna Melissa Schlitter ${ }^{1,11}$, Kee-Taek Jang ${ }^{2,11}$, Günter Klöppel ${ }^{1}$, Burcu Saka ${ }^{3}$, Seung-Mo Hong ${ }^{4}$, Hyejeong Choi $^{3}$, George Johan Offerhaus ${ }^{5}$, Ralph H Hruban ${ }^{6}$, Yoh Zen ${ }^{7}$, Björn Konukiewitz ${ }^{1}$, Ivonne Regel ${ }^{8}$, Michael Allgäuer ${ }^{1}$, Serdar Balci ${ }^{3}$, Olca Basturk ${ }^{9}$, Michelle D Reid ${ }^{3}$, Irene Esposito ${ }^{10}$ and Volkan Adsay ${ }^{3}$

${ }^{1}$ Institute of Pathology, Technische Universität München, München, Germany; ${ }^{2}$ Department of Pathology, Samsung Medical Center, Sungkyunkwan University School of Medicine, Seoul, Korea; ${ }^{3}$ Department of Pathology, Emory University School of Medicine, Atlanta, GA, USA; ${ }^{4}$ Department of Pathology, Ulsan University Hospital, University of Ulsan, College of Medicine, Seoul, Korea; ${ }^{5}$ Department of Pathology, University Medical Center, Utrecht, The Netherlands; ${ }^{6}$ Department of Pathology, The Sol Goldman Pancreatic Cancer Research Center, Johns Hopkins University School of Medicine, Baltimore, MD, USA; ${ }^{7}$ Department of Diagnostic Pathology, Kobe University, Kobe, Japan; ${ }^{8}$ Department of Surgery, Technische Universität München, München, Germany; ${ }^{9}$ Department of Pathology, Memorial Sloan-Kettering Cancer Center, New York, NY, USA and ${ }^{10}$ Institute of Pathology, Medical University of Innsbruck, Innsbruck, Austria

Intraductal tubulopapillary neoplasm is a well-established entity in the pancreas. A similar, if not identical, tumor occurs also in the biliary tract. We conducted a multicenter study of 20 such lesions, focusing on their clinicopathologic characteristics and molecular profile. Biliary intraductal tubulopapillary neoplasms were seen in patients in their 60s (mean 62 years). The tumors were intrahepatic $70 \%$, extrahepatic $10 \%$, and perihilar $20 \%$; mean tumor size was $6.9 \mathrm{~cm}$. Histologically, all intraductal tubulopapillary neoplasms showed, in addition to their typical tubular pattern, solid areas $(70 \%)$ or abortive papillae $(50 \%)$. Necrosis was common $(85 \%)$, predominantly focal $(40 \%)$, and with 'comedocarcinoma-like pattern' in $40 \%$. Immunohistochemically, these neoplasms were characterized by the expression of MUC1 $(80 \%)$ and MUC6 $(30 \%)$ and by the absence of MUC2 and MUC5AC. Associated invasive carcinomas were present in $16(80 \%)$, mainly conventional tubular adenocarcinoma $(50 \%)$. The molecular alterations observed included CDKN2A/p16 (intraductal components 44\%, invasive $33 \%$ ) and TP53 (intraductal components $17 \%$, invasive $9 \%$ ). Mutations in KRAS (intraductal $6 \%$, invasive $0 \%$ ), PIK3CA (intraductal $6 \%$, invasive $0 \%$ ), and loss of SMAD4/DPC4 (intraductal $7 \%$, invasive $0 \%$ ) were rare. No alterations/mutations were identified in IDH1/2, BRAF, GNAS, EGFR, HER2, and $\beta$-catenin. Follow-up information was available for 17 patients (85\%) with mean follow-up 44 months. Overall combined survival rates showed favorable prognosis: 1 year $100 \%, 3$ years $90 \%$, and 5 years $90 \%$. In conclusion, despite the relatively high incidence of invasive carcinoma $(80 \%)$, available follow-up suggests that biliary intraductal tubulopapillary neoplasms have an indolent behavior. Molecular analyses highlight the low prevalence of alterations of common oncogenic signaling pathways in intraductal tubulopapillary neoplasm. Further studies using whole-exome sequencing are required to discover yet unknown molecular changes and to understand the carcinogenesis of intraductal tubulopapillary neoplasms. Modern Pathology (2015) 28, 1249-1264; doi:10.1038/modpathol.2015.61; published online 26 June 2015

Correspondence: Dr V Adsay, MD, Anatomic Pathology, Emory University Hospital, 1364 Clifton Road, NE, Room H-180B, Atlanta, GA 30322, USA.

E-mail: volkan.adsay@emory.edu

${ }^{11}$ Co-contributing primary authors of the manuscript.

Received 1 February 2015; Received 28 April 2015; accepted 29 April 2015; published online 26 June 2015
Invasive bile duct carcinoma (cholangiocarcinoma) is a malignant disease with dismal prognosis and limited treatment options. ${ }^{1-3}$ Some of these invasive carcinomas arise from non-invasive intraductal precursor lesions ${ }^{4}$ that are similar to intraductal precursor lesions of the pancreas., ${ }^{3,5,6}$ In the biliary 
tree, these precursor lesions are called: biliary intraepithelial neoplasia and intraductal papillary neoplasms of the bile duct. ${ }^{7}$ While biliary intraepithelial neoplasia are the microscopic/incidental form of low(biliary intraepithelial neoplasia-1) to high-grade dysplasia (biliary intraepithelial neoplasia-3/'carcinoma in-situ'), intraductal papillary neoplasm of the bile duct is the term used for the tumoral intraepithelial neoplasms that are grossly visible, prominent intraductal tumors with predominantly papillary growth. ${ }^{2,4}$ Based on the cell type and mucin expression profile, four intraductal papillary neoplasms of the bile duct subtypes, similar to the subtypes of pancreatic intraductal papillary mucinous neoplasms, can be distinguished: pancreatobiliary, gastric, intestinal, and oncocytic. ${ }^{8,9}$ We have recently shown that the progression of non-invasive intraductal papillary neoplasms of the bile duct to invasive carcinoma involves common molecular pathways. ${ }^{9}$

In the pancreas, in addition to the bettercharacterized intraductal papillary mucinous neoplasms, intraductal neoplasm was recently included in the World Health Organization classification: intraductal tubulopapillary neoplasm. ${ }^{10}$ Pancreatic intraductal tubulopapillary neoplasms are rare intraductal neoplasms with minimal or no mucin production, and are histologically characterized by tubular architecture and only sparse formation of papillary elements. ${ }^{10-12}$ Although associated invasive carcinoma is present in approximately $40 \%$ of reported pancreatic intraductal tubulopapillary neoplasms, the clinical behavior seems to be less aggressive compared with classical ductal adenocarcinoma of the pancreas. ${ }^{10}$ Recent studies on the molecular carcinogenesis of pancreatic intraductal tubulopapillary neoplasms revealed that oncogenic pathways that are commonly altered in intraductal papillary mucinous neoplasms are rarely mutated in pancreatic intraductal tubulopapillary neoplasms, with the highest mutation prevalence in the PIK3CA gene $(0-21.4 \%)$ and only rare mutations in KRAS (0$7.1 \%)$ and $B R A F(0-7.1 \%) .{ }^{13-15}$ In a recent study based on the targeted next-generation sequencing of 11 pancreatic intraductal tubulopapillary neoplasms, no mutations were identified in a panel of 300 key cancer-associated genes including KRAS, GNAS, and $R N F 3$ genes. In fact, three cases $(27 \%)$ did not reveal any mutations in the tested genes and only two specific genes were mutated in more than one case: $M L L 2$ and $M L L 3$, each identified in two cases. ${ }^{16}$ The biliary counterpart of pancreatic intraductal tubulopapillary neoplasm is poorly recognized. In 2010, Park et $a l^{17}$ described a single case of biliary carcinoma resembling pancreatic intraductal tubulopapillary neoplasm with tubulopapillary growth, MUC1 expression (in the absence of MUC2, 5AC and 6). Two years later, Zen et $a 1^{18}$ reported two cases of intraductal tubulopapillary tumors of the intrahepatic bile duct system with similar immunophenotype (MUC1 and 6 positivity) and genotype (KRAS and BRAF wild type). Recently, Katabi et a ${ }^{19}$ presented 10 examples of intraductal biliary neoplasms with predominantly tubular architecture similar to pancreatic intraductal tubulopapillary neoplasms under the heading of 'intraductal tubular neoplasms. ${ }^{19}$ In detail, the neoplasms showed a pancreatobiliary epithelial phenotype (expression of MUC1 and MUC6, the absence of MUC2 and MUC5AC) had intact SMAD4 and TP53 function and were associated with a favorable prognosis. Tumors similar to pancreatic intraductal tubulopapillary neoplasms also occur in the gallbladder and have recently been analyzed as a subset under the heading of intracholecystic papillary tubular neoplasm; $; 0$ however, those with more tubular nonmucinous configuration may be a distinct entity. ${ }^{21}$

As data on the histological spectrum of biliary intraductal tubulopapillary neoplasms, their clinical behavior and the molecular carcinogenesis are still limited due to the small number of reported cases, we conducted a study in a large international intraductal tubulopapillary neoplasm cohort including patients from Europe, United States, Japan, and Korea. We focused on histomorphology, clinical prognosis and present a systematic investigation of common oncogenic pathways in the carcinogenesis of this rare entity.

\section{Materials and methods}

The study was approved by the ethics committees and the institutional review boards of the respective institutions.

\section{Patient Selection}

Diagnostic criteria for biliary intraductal tubulopapillary neoplasms were based on the established criteria for pancreatic intraductal tubulopapillary

Table 1 Diagnostic criteria

Definition of intraductal tubulopapillary neoplasm of the bile duct

Neoplasm that is

growing within the bile duct system (extra- or intrahepatic bile duct)

preinvasive (dysplastic)

associated with invasive carcinoma (optional)

mass-forming, exophytic

presenting predominantly as non-mucinous tubular units with/without sheet-like growth $(\geq 70 \%)$

presenting only minimal or lack of papillary growth $(\leq 30 \%)$ 
neoplasms (Table 1). ${ }^{10}$ Intraductal tumors of the extra and/or intra-hepatic bile duct system fulfilling the newly defined diagnostic criteria (see below) were retrieved from the authors' institutional and consultation files and were included in the study. Cases with overt papillary growth or mucinous pyloric gland pattern, small microscopic lesions (not forming tumoral intraepithelial neoplasia), and/or those with MUC5AC expression, e.g., intraductal papillary neoplasms of the bile duct, ${ }^{9}$ biliary mucinous cystic neoplasms, ${ }^{22}$ biliary intraepithelial neoplasia, ${ }^{23}$ as well as intraductal neoplasms of the ampulla were all excluded. $^{24}$ All tumors were reviewed by four pathologists (AMS, IE, MDR, and VA) regarding their classification and the presence or absence of an associated invasive lesion. In case of discrepant diagnoses, the respective cases were assessed together and the immunohistochemical expression profile served as basis for the final classification.

The study cohort consisted of 20 patients from different (American, Asian, and European) institutions: 8 cases from the Department of Pathology, Emory University School of Medicine, Atlanta, Georgia, USA; 4 cases from the Department of Pathology, Samsung Medical Center, Sungkyunkwan University School of Medicine, Seoul, Korea; 3 cases from the Institute of Pathology and from the Institute's consultation files, Technische Universität München, Germany; 2 cases from the Department of Pathology, Ulsan University Hospital, University of Ulsan, College of Medicine, Seoul, Korea; 1 case from University of Minnesota; 1 case from the Department of Pathology, University Medical Center, Utrecht, The Netherlands; and 1 case from the Institute of Liver Studies, King's College Hospital, London, UK.

\section{Clinical Data and Follow-Up}

Clinical, demographic, and macroscopic information were obtained by review of the medical charts and pathology reports. Follow-up on the patients' conditions was obtained through chart review, or by contacting the primary physicians. Two patients with perioperative mortality within the first 90 days after surgery ${ }^{25}$ were excluded from survival analysis.

\section{Histomorphological Analysis}

All specimens were fixed in formalin, embedded in paraffin, cut in 3- to 5- $\mu$ m-thick sections and stained with hematoxylin and eosin. Histological and immunohistochemical analyses were performed on representative tissue blocks of the intraductal and, if present, invasive areas. An average of four slides with non-invasive and, if applicable, invasive lesions were available for review per case (range 1-7).

\section{Grading and Estimation of Invasion}

The degree of dysplasia was graded based on the criteria used for intraepithelial lesions of the pancreatobiliary tract. Additionally, intraductal tumors were also graded according to the degree of tubule formation $(1:>75 \%, 2: 10-75 \%$, 3: less than $10 \%$ ), nuclear pleomorphism, and mitotic count referring to the grading of breast cancer $^{26}$ in lowgrade (3-4 out of 9 points), moderate (5-6 out of 9 points), and high-grade (7-9 out of 9 points) lesions.

Grading of invasive carcinomas followed the recommendations of the World Health Organization. ${ }^{2,20}$ The amount of invasive carcinoma relative to non-invasive component was estimated according to the available material (less than 10\%: microinvasion; $10-50 \%$ as substantial, and extensive, if $>50 \%$ ).

\section{Growth Pattern}

Growth pattern in the intraductal lesions was evaluated for the fraction of tubular, solid, and papillary structures. Additional features including clear-cell parathyroid-like areas, acidophilic (colloid-like) secretions creating thyroid follicular pattern, oncocytoid cytology (abundant, acidophilic, granular cytoplasm with round nuclei and single, prominent, eccentric nucleoli), intraluminal mucin, necrosis (also recorded arbitrarily as spotty/focal $(<25 \%),>25 \%$ as widely extensive or with 'comedocarcinoma-like' pattern) as well as luminal calcifications/psammoma bodies, hyaline globules, and intraluminal secretory precipitations were also recorded.

Invasive carcinomas were classified according to their predominant morphology as conventional tubular (small tubular pattern), tubular-cystic (formation of large cystic units, some with intratubular niduses), and clear cell. Some cases had smooth-contoured nodular infiltration pattern closely mimicking preinvasive (non-invasive) tumors, typically also showing central comedo-like necrosis. We termed the latter as 'in situ-like with comedonecrosis.' Additionally, an attempt was made to further classify the tubular type invasion into the recently proposed categories of 'cholangiolar' or 'bile duct' pattern. ${ }^{27}$

\section{Immunohistochemical Analysis}

Intraductal lesions and invasive carcinomas were evaluated separately by immunohistochemistry using the following antibodies that have been shown to be differentially expressed in pancreatobiliary neoplasms:9,28-30 anti-MUC1 (Novocastra, Newcastle upon Tyne, UK; 1:160), anti-MUC2 (Novocastra; 1:100), anti-MUC5AC (Leica Microsystems, Bannockburn, IL, USA; 1:200), and anti-MUC6 (Leica Microsystems; 1:80), anti-EGFR (Dako, Carpinteria, CA, USA; RTU ready-to-use), anti-TP53 (Dako; 1:80), anti-HER2 (Dako; 1:80), anti-SMAD4 (Santa Cruz Biotechnology, Santa Cruz, CA, USA; 1:400), antiCDKN2A/p16 (CINtec, Ventana Medical Systems, Tucson, AZ, USA; ready-to-use), and anti-CDX2 (Biogenex, San Ramon, CA, USA; 1:200). All 
immunolabeling was run on an automated immunostainer according to the company's protocols for open procedures with slight modifications. The immunohistochemical labeling of the antibodies listed above was evaluated as described before. ${ }^{9}$

\section{Molecular Analysis}

DNA extraction was performed separately in manually microdissected intraductal lesions and invasive carcinomas, where applicable. Molecular analyses of KRAS (exons 2 and 3), GNAS (exon 8), BRAF (codon 600), and PIK3CA (exon 9 and 20) were performed by a combination of real-time PCR with high-resolution melting analysis and direct sequencing of samples as described before (KRAS, GNAS and BRAF; 9 PIK3CA ${ }^{31}$ ). For IDH1 (exon 4) and IDH2 (exon 4) analyses, the following primers were designed referring to Tefferi et al ${ }^{32}$ IDH1-F-T7: 5'-TAATACGACT CACTATAGGCGGTCTTCAGAGAAGCCATT-3', IDH1R: 5'-ACATTATTGCCAACATGAC-3', IDH2-132-F-T7: 5'-TAATACGACTCACTATAGGGCTGAAGAAGAT GTGGAA-3'， IDH2-132-R: 5'-TGATGGGCTCCCGG AAGA-3', IDH2-170-F: 5'-CCAAGCCCATCACCAT TG-3', IDH2-170-R-T7: 5'-TAATACGACTCACTAT AGGcccaggtcagtggatccc-3'. Loss of heterozygosity (LOH) of CDKN2A/p16 locus was analyzed with quantitative real-time PCR of different genomic regions, distal and proximal to $C D K N 2 A$, as well as the $C D K N 2 A$ locus itself according to Trkova et al. ${ }^{33}$ Amplification of the distal or proximal region was compared with the CDKN2A locus $(\Delta \mathrm{Ct})$ and quantified as normal $(>0.75)$, LOH $(0.75-0.1)$, and homozygous deletion $(<0.1)$.

\section{Statistical Analysis}

Statistical analyses were performed by employing SPSS Statistics software Version 20.0 and SAS software version 9.3. Survival data were analyzed using the Kaplan-Meier method and the estimated 1-, 3-, and 5-year survival probabilities were reported. Differences in survival curves were assessed by the log-rank test and the Wilcoxon test, which places emphasis on differences in early survival. All statistical tests were conducted two sided at a 0.05 level of significance.

Survival data were compared with a previously published intraductal papillary neoplasm of the bile duct and cholangiocarcinoma cohort. ${ }^{9}$ Patients with perioperative mortality within the first 90 days after surgery $^{25}$ were excluded from survival analysis.

\section{Results}

\section{General Characteristics}

Intraductal tubulopapillary neoplasms were rare. In the files of Emory University, 8 cases were identified among 240 bile duct cancers. At the Institute of
Pathology, Technische Universität München, Munich, Germany, between the years 2000 and 2015 , only 2 cases with intraductal tubulopapillary neoplasms of the bile duct were identified, while 15 intraductal papillary neoplasms of the bile duct were identified in the same database during that period, indicating that they constitute approximately $15 \%$ of intraductal neoplasia of the bile ducts.

Twenty patients fulfilled the inclusion criteria (Table 1) of biliary intraductal tubulopapillary neoplasm. The general characteristics of the intraductal tubulopapillary neoplasm patients are summarized in Tables 2 and 3 . Twelve patients were female and seven male (the gender was unknown to the authors in one patient), with a mean age at diagnosis of 62 years (range 42-75). Fourteen were intrahepatic, four hilar, and two distal common bile duct. The noninvasive component of the intraductal tubulopapillary neoplasms ranged from 1.5 to $15 \mathrm{~cm}$ (mean, $6.9 \mathrm{~cm}$ ). Associated invasive carcinoma was present in $16 / 20$ patients $(80 \%)$ and lymph-node metastases in 2 of 12 patients with lymph nodes obtained for examination. All patients underwent major hepatic surgery: $75 \%$ hemihepatectomy (12/16), 19\% hemihepatectomy with bile duct resection (3/16), and $6 \%$ liver transplantation (1/16). The type of operation was not specified in the surgical pathology reports of four patients. The documented chief symptoms and signs at presentation were jaundice, abdominal pain, and weight loss. The clinical diagnoses rendered were cholangiocarcinoma in $57 \%(8 / 14)$, intraductal

Table 2 General patient characteristics and clinical outcomes

\begin{tabular}{|c|c|c|}
\hline & Overall & $\%$ \\
\hline$N$ & 20 & \\
\hline Median age at diagnosis in years (range) & $62(42-75)$ & \\
\hline Male & $7 / 19$ & 37 \\
\hline Female & $12 / 19$ & 63 \\
\hline \multicolumn{3}{|l|}{ Clinical follow-up in months } \\
\hline Number of patients with follow-up & $17 / 20$ & 85 \\
\hline Median follow-up in months (range) & $44(1-150)$ & \\
\hline Perioperative death & $2 / 17$ & 12 \\
\hline 1-year survival & & 100 \\
\hline 3-year survival & & 90 \\
\hline 5-year survival & & 90 \\
\hline \multicolumn{3}{|l|}{ Localization } \\
\hline Intrahepatic bile duct & $14 / 20$ & 70 \\
\hline Extrahepatic bile duct & $2 / 20$ & 10 \\
\hline Perihilar or hilar bile duct & $4 / 20$ & 20 \\
\hline Tumor size in cm (range) & $6.9(1.5-15)$ & \\
\hline $\begin{array}{l}\text { Intraductal tubulopapillary neoplasms, } \\
\text { non-invasive }\end{array}$ & $4 / 20$ & 20 \\
\hline $\begin{array}{l}\text { Intraductal tubulopapillary neoplasms } \\
\text { with associated invasive } \\
\text { adenocarcinoma }\end{array}$ & $16 / 20$ & 80 \\
\hline \multicolumn{3}{|l|}{ Lymph nodes } \\
\hline No & $10 / 20$ & 50 \\
\hline N1 & $2 / 20$ & 10 \\
\hline NX & $8 / 20$ & 40 \\
\hline
\end{tabular}




\begin{tabular}{|c|c|c|c|c|c|c|c|c|c|c|}
\hline Case & $\begin{array}{l}\text { Age of onset } \\
\text { (years) }\end{array}$ & Gender & Localization & $\begin{array}{l}\text { Tumor size } \\
\qquad(\mathrm{cm})\end{array}$ & $\begin{array}{l}\text { Invasive } \\
\text { carcinoma }\end{array}$ & Type of invasive carcinoma & $\begin{array}{l}\text { Lymph } \\
\text { nodes }\end{array}$ & $\begin{array}{l}\text { Survival in } \\
\text { months }\end{array}$ & Status & Molecular profile \\
\hline \# 1 & 72 & $\mathrm{~F}$ & $\begin{array}{l}\text { Perihilar bile } \\
\text { duct }\end{array}$ & 5.5 & Yes & Tubular adenocarcinoma & No & 57 & NED & \\
\hline$\# 2$ & 66 & M & $\begin{array}{l}\text { Intrahepatic bile } \\
\text { duct }\end{array}$ & 1.5 & No & & NX & 14 & NED & \\
\hline$\# 3$ & 75 & $\mathrm{~F}$ & $\begin{array}{l}\text { Extraheptic bile } \\
\text { duct }\end{array}$ & 7.5 & No & & No & 31 & DOD & $\begin{array}{l}\text { Loss of p16+loss of SMAD4+focal } \\
\text { TP53 overexpression (intraductal) }\end{array}$ \\
\hline$\# 4$ & 59 & $\mathrm{~F}$ & $\begin{array}{l}\text { Intrahepatic bile } \\
\text { duct }\end{array}$ & 6 & Yes & Tubular adenocarcinoma & NX & 33 & NED & Loss of p16 (intraductal+invasive) \\
\hline \# 5 & 48 & $\mathrm{M}$ & $\begin{array}{l}\text { Intrahepatic bile } \\
\text { duct }\end{array}$ & 15 & Yes & Tubular adenocarcinoma & No & 2 & NED & \\
\hline \# 6 & 66 & M & $\begin{array}{l}\text { Intrahepatic bile } \\
\text { duct }\end{array}$ & 2.5 & No & & No & 80 & NED & $\begin{array}{l}\text { Focal TP53 overexpression } \\
\text { (intraductal) }\end{array}$ \\
\hline \# 7 & 72 & $\mathrm{~F}$ & $\begin{array}{l}\text { Intrahepatic bile } \\
\text { duct }\end{array}$ & 6.7 & Yes & Tubular adenocarcinoma & NX & 52 & NED & \\
\hline \# 8 & 54 & $\mathrm{~F}$ & $\begin{array}{l}\text { Intrahepatic bile } \\
\text { duct }\end{array}$ & 15 & Yes & Tubular adenocarcinoma & NX & LFU & LFU & \\
\hline \# 9 & 42 & M & $\begin{array}{l}\text { Extraheptic bile } \\
\text { duct }\end{array}$ & 6 & Yes & Tubular adenocarcinoma & No & LFU & LFU & Loss of p16 (intraductal) \\
\hline \# 10 & Unknown & Unknown & $\begin{array}{l}\text { Perihilar bile } \\
\text { duct }\end{array}$ & 8.5 & Yes & $\begin{array}{l}\text { Tubular adenocarcinoma, } \\
\text { clear cell variant }\end{array}$ & N1 & LFU & LFU & $\begin{array}{l}\text { PIK3CA E545K (intraductal), loss } \\
\text { of p16+focal TP53 overexpression } \\
\text { (invasive) }\end{array}$ \\
\hline \# 11 & 68 & $\mathrm{~F}$ & $\begin{array}{l}\text { Perihilar bile } \\
\text { duct }\end{array}$ & 5.5 & Yes & Tubular adenocarcinoma & No & 124 & NED & Loss of p16 (intraductal+invasive) \\
\hline \# 12 & 64 & M & $\begin{array}{l}\text { Intrahepatic bile } \\
\text { duct }\end{array}$ & 9 & Yes & Tubular adenocarcinoma & No & 1 & POD & \\
\hline \# 13 & 57 & $\mathrm{~F}$ & $\begin{array}{l}\text { Intrahepatic bile } \\
\text { duct }\end{array}$ & 7 & Yes & $\begin{array}{l}\text { In situ-like with } \\
\text { comedonecrosis }\end{array}$ & NX & 39 & NED & \\
\hline \# 14 & 65 & $\mathrm{~F}$ & $\begin{array}{l}\text { Intrahepatic bile } \\
\text { duct }\end{array}$ & 5 & Yes & $\begin{array}{l}\text { In situ-like with } \\
\text { comedonecrosis }\end{array}$ & N1 & 16 & NED & LOH $p 16$ (intraductal) \\
\hline \# 15 & 55 & $\mathrm{~F}$ & $\begin{array}{l}\text { Intrahepatic bile } \\
\text { duct }\end{array}$ & 7 & Yes & $\begin{array}{l}\text { In situ-like with } \\
\text { comedonecrosis }\end{array}$ & No & 1 & POD & \\
\hline \# 16 & 58 & $\mathrm{M}$ & $\begin{array}{l}\text { Intrahepatic bile } \\
\text { duct }\end{array}$ & 5 & Yes & $\begin{array}{l}\text { In situ-like with } \\
\text { comedonecrosis }\end{array}$ & No & 11 & NED & \\
\hline \# 17 & 64 & M & $\begin{array}{l}\text { Perihilar bile } \\
\text { duct }\end{array}$ & $\mathrm{NN}$ & Yes & Tubular-cystic & NX & 150 & NED & Loss of p16 (intraductal) \\
\hline \# 18 & 67 & $\mathrm{~F}$ & $\begin{array}{l}\text { Intrahepatic bile } \\
\text { duct }\end{array}$ & 6.5 & Yes & Tubular-cystic & NX & 34 & NED & \\
\hline \# 19 & 72 & $\mathrm{~F}$ & $\begin{array}{l}\text { Intrahepatic bile } \\
\text { duct }\end{array}$ & 5.5 & No & & NX & 107 & NED & $\begin{array}{l}\text { Loss of p16+KRAS G12D } \\
\text { (intraductal) }\end{array}$ \\
\hline$\# 20$ & 63 & $\mathrm{~F}$ & $\begin{array}{l}\text { Intrahepatic bile } \\
\text { duct }\end{array}$ & 7.1 & Yes & Tubular adenocarcinoma & No & 1 & NED & $\begin{array}{l}\text { Focal TP53 overexpression } \\
\text { (intraductal) }\end{array}$ \\
\hline
\end{tabular}


cholangiocarcinoma in 29\% (4/14), gallbladder carcinoma in $7 \%(1 / 14)$, and tumor of the adrenal gland in $7 \%(1 / 14)$.

\section{Pathologic Findings}

On gross examination nodules were seen filling the ducts (Figure 1). In some areas, the ducts were only

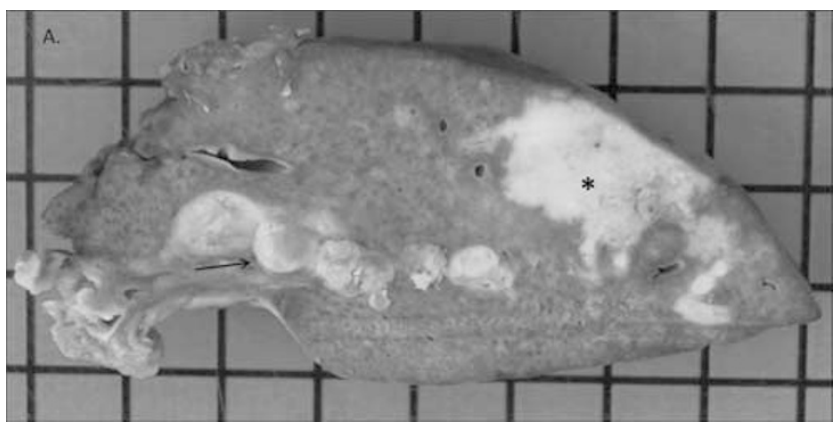

Figure 1 Gross morphology: intrahepatic intraductal tubulopapillary neoplasm showing dilated bile ducts (arrow) filled with white tan granular nodules as well as firm white, scirrhous invasive tumor $(*)$. partially filled by the intraductal lesion, and the duct contours were relatively preserved, confirming the intraductal nature of the tumor. In others, the duct lumens were filled entirely by the intraductal process, which also obscured the duct wall, and thus it was difficult to appreciate that the nodules were truly intraductal. Foci of invasion were typically represented by firm, white schirrous nodules showing irregular borders, but they were well demarcated from the hepatic parenchyma (Figure 1). Punctate or geographic foci of necrosis were noted in some cases.

The microscopic findings in both non-invasive and invasive cases are shown in Figures 2-4, and are summarized in Table 4. All intraductal tubulopapillary neoplasms were characterized by large, smoothcontoured nodules (Figures 2a-e) composed of prominent, relatively small, back-to-back tubular units (Figures 2c-i, 3a, and b). In the majority of the cases, there was only minimal or no visible stroma in the nodules. In $75 \%$ of the cases, the tubular structures were focally replaced by more solid/poorly-differentiated components (Figures 2b, $\mathrm{d}$, and g). In some of these solid areas, more elongated (spindle shaped) nuclei with streaming
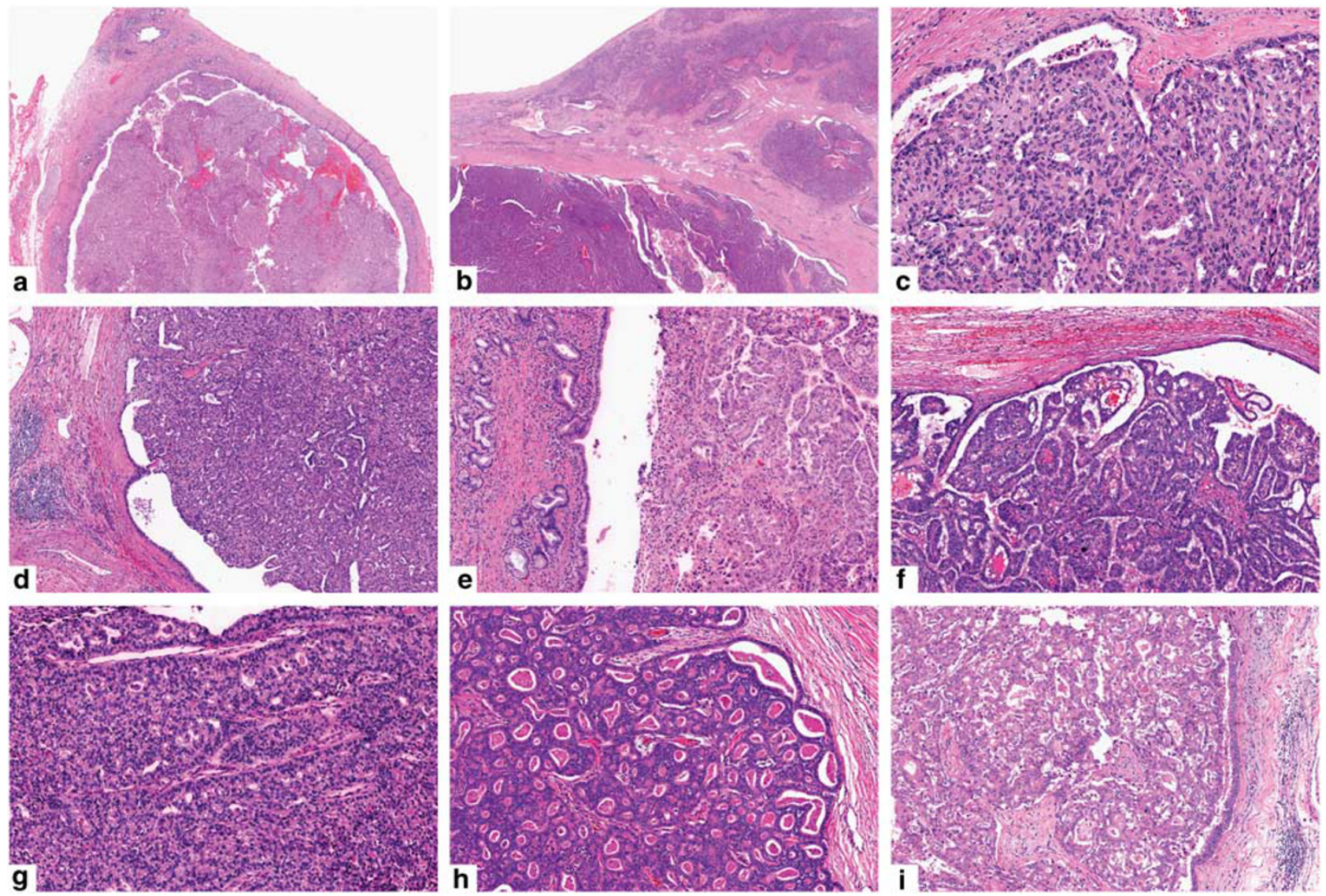

Figure 2 Histological pattern of biliary intraductal tubulopapillary neoplasms: (a) Intraductal polypoid mass with preservation of the native duct epithelium. (b) Intraductal nature is manifested as solid compact nodular growth (which in this case is also associated with invasive carcinoma in the upper right of the image). (c-e) Characteristic tubular pattern of intraductal tubulopapillary neoplasm with solid/tubular areas (d). Additional patterns: (f) abortive papillae formation, (g) parathyroid-like areas with more subtle acinar pattern, (h) thyroid follicular, and (i) oncocytoid pattern (see Figure $3 \mathrm{~b}$ for high power). 

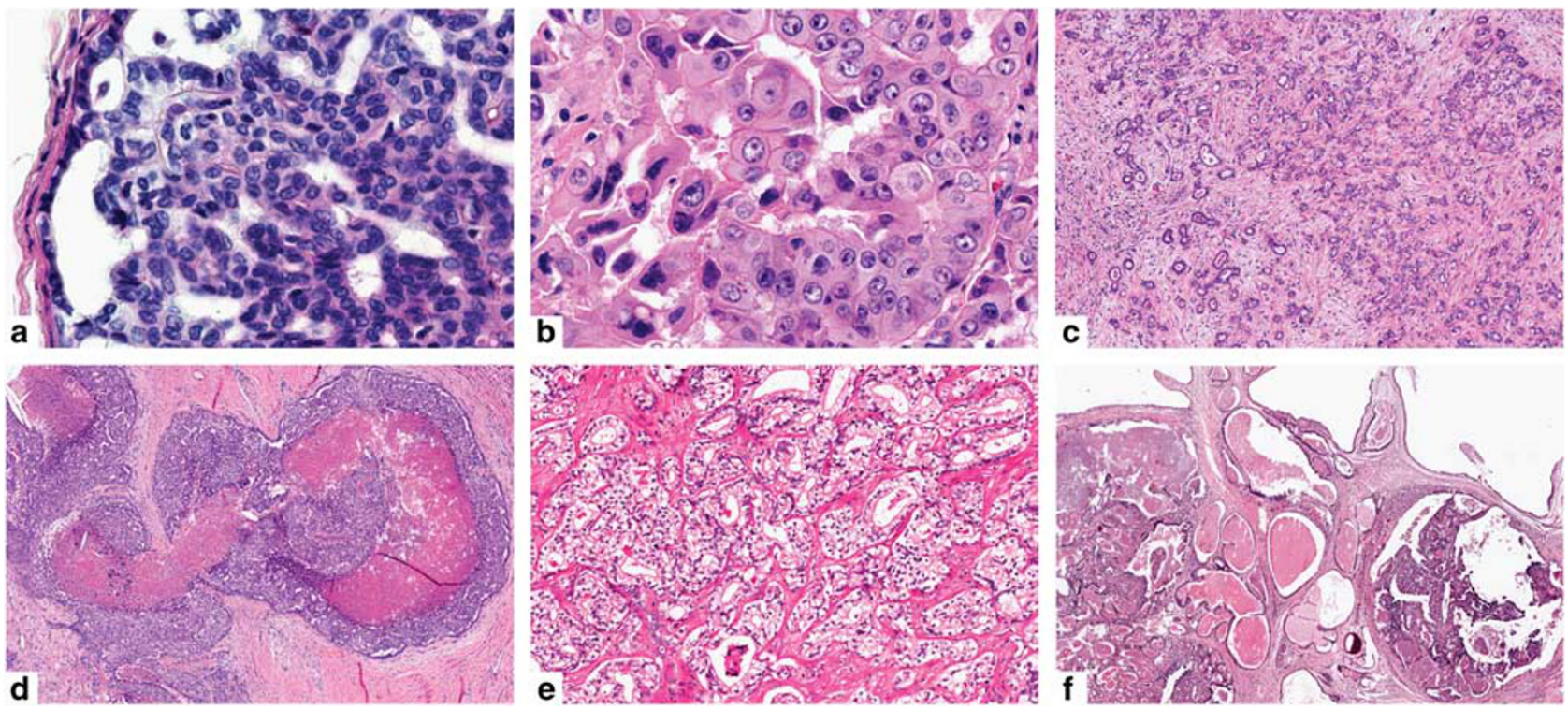

Figure 3 Grading of biliary intraductal tubulopapillary neoplasms and morphology of associated invasive carcinomas: (a) low-to-moderate grade intraductal tubulopapillary neoplasm and (b) high-grade intraductal tubulopapillary neoplasm (high power of Figure 2i). Morphology of associated invasive carcinoma: (c) conventional tubular cholangiocarcinoma, (d) in situ-like carcinoma with comedonecrosis, and (e) tubular adenocarcinoma, clear cell variant. (f) Large cystic units forming sieve-like pattern with focal transition to more conventional intraductal tubulopapillary neoplasm-type nodules.
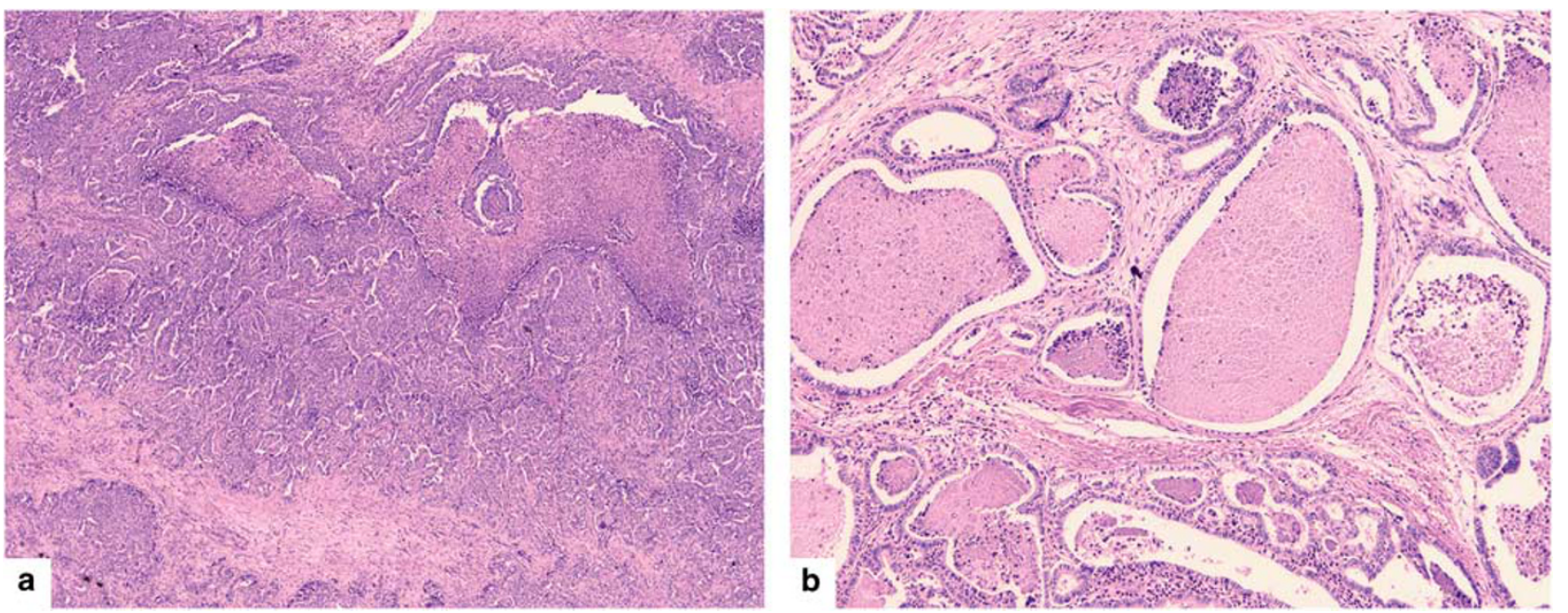

Figure 4 High power view of distinct patterns of invasion in biliary intraductal tubulopapillary neoplasm: (a) In situ-like invasive carcinoma with comedonecrosis. Large sheet of tumor cells with central comedonecrosis mimics an 'in-situ' carcinoma and peripherally invades the surrounding stroma as arborizing, abortive tubular units. (b) Invasive tubulocystic carcinoma component shows variably sized, focally cystic tubular units with luminal necrosis and bland epithelium infiltrating stroma.

could be observed (Figure 2c). Minor, abortive papillary elements (Figure 2f) were observed in $50 \%$ of the cases, but by definition, none of the cases had any well-formed tall papillary units. One intraductal tubulopapillary neoplasm case had a pattern similar to sclerosing papilloma as seen in the breast (Figure 5f).

Most of the neoplastic cells were low cuboidal to minimally columnar (Figure 3a). Nucleoli were prominent in some cases but not all (Figure 3b). The cytoplasm varied in amount and texture from case to case and between different areas of the same case, but typically, was moderate and amphophilic. In 15\%, there were foci with oncocytoid cytoplasm (Figure 3b). In $15 \%$, there were foci of clear cells which, together with the tubular configuration, created a picture highly reminiscent of parathyroid cells (Figure 2g). Homogenous acidophilic intraluminal secretions resembling colloid of thyroid follicles (Figure $2 \mathrm{~h}$ ) were noted in $11 \%$. Scattered small calcifications and fullydeveloped psammoma-bodies were seen in 15\%. The so-called Mallory-like hyaline globules of the type seen in hepatic or kidney cancers ${ }^{34}$ were noted in $5 \%$.

Using the dysplasia grading criteria in the pancreatobiliary tract, all cases ultimately qualified as 
Table 4 Histopathology of intraductal tubulopapillary neoplasms and associated invasive carcinomas

\begin{tabular}{|c|c|c|}
\hline & Overall & $\%$ \\
\hline \multicolumn{3}{|l|}{ Intraductal tumor } \\
\hline \multicolumn{3}{|l|}{ Growth pattern } \\
\hline Tubular & $20 / 20$ & 100 \\
\hline Solid/poorly formed tubular & $15 / 20$ & 75 \\
\hline Papillary & $10 / 20$ & 50 \\
\hline \multicolumn{3}{|l|}{ Additional features } \\
\hline Clear cell/parathyroid-like & $3 / 20$ & 15 \\
\hline Follicular/thyroid-like & $2 / 20$ & 10 \\
\hline Oncocytoid* & $3 / 20$ & 15 \\
\hline Small calcifications/psammomabodies & $3 / 20$ & 15 \\
\hline Hyaline globules & $1 / 20$ & 5 \\
\hline Precipitations & $2 / 20$ & 10 \\
\hline Intraluminal mucin & $1 / 20$ & 5 \\
\hline Necrosis & $17 / 20$ & 85 \\
\hline Spotty/focal & $8 / 20$ & 40 \\
\hline Comedo-like & $8 / 20$ & 40 \\
\hline Widely extensive & $1 / 20$ & 5 \\
\hline \multicolumn{3}{|l|}{ Grading } \\
\hline Low-to intermediate grade & $12 / 20$ & 60 \\
\hline High-grade & $8 / 20$ & 40 \\
\hline \multicolumn{3}{|l|}{ Invasive carcinoma } \\
\hline \multicolumn{3}{|l|}{ Estimated invasion (\%) } \\
\hline Overall & \multicolumn{2}{|c|}{$52 \%(5-90 \%)$} \\
\hline Microinvasion $(<10 \%)$ & $3 / 16$ & 19 \\
\hline $10-50 \%$ & $3 / 16$ & 19 \\
\hline$>50 \%$ & $10 / 16$ & 63 \\
\hline Tubular adenocarcinoma & $9 / 16$ & 50 \\
\hline In situ-like with comedonecrosis & $4 / 16$ & 25 \\
\hline Tubular adenocarcinoma, clear cell variant & $1 / 16$ & 6 \\
\hline Tubular-cystic & $2 / 16$ & 13 \\
\hline \multicolumn{3}{|l|}{ Grading } \\
\hline G1 & $7 / 16$ & 44 \\
\hline G2 & $8 / 16$ & 50 \\
\hline G3 & $1 / 16$ & 6 \\
\hline
\end{tabular}

Boldface indicates sub-results that highlight the total overall.

Table 5 Clinicopathological characteristics of patients with intraductal tubulopapillary neoplasms with 'in situ-like' invasive carcinoma with comedonecrosis

\begin{tabular}{lccl}
\hline & $\begin{array}{c}\text { Percentage of } \\
\text { invasive } \\
\text { carcinoma }\end{array}$ & $\begin{array}{c}\text { Grading } \\
\text { (invasive } \\
\text { carcinoma) }\end{array}$ & $\begin{array}{l}\text { Lymph } \\
\text { nodes }\end{array}$ \\
\hline Intrahepatic & 70 & $\mathrm{G} 2$ & $\mathrm{NX}$ \\
Intrahepatic & 70 & $\mathrm{G} 2$ & $\mathrm{~N} 1(1 / 24)$ \\
Intrahepatic & 70 & $\mathrm{G} 2$ & No $(0 / 4)$ \\
Intrahepatic & 90 & $\mathrm{G} 3$ & N0 $(0 / 5)$ \\
\hline
\end{tabular}

high-grade dysplasia because, although there was cytologic uniformity in most cases, there were also at least some foci with striking architectural complexity (Figures 2c-i, 3a, and b) and the nuclei were round and atypical. Using a modified grading system based on the Bloom-Richardson criteria for breast carcinomas described above, $60 \%$ of the intraductal neoplastic changes qualified as low-to-intermediate grade (Figure 3a), and the remaining $40 \%$ as high grade (Figure $3 b$ ).

Tumor necrosis was noted in $85 \%$ of the cases, either as spotty necrosis (40\%) or as central necrosis creating a picture akin to mammary comedo carcinomas $(40 \%)$. Extensive necrosis of the tumor was uncommon $(5 \%)$.

\section{Invasive Carcinoma Arising in Intraductal Tubulopapillary Neoplasms}

Associated invasive carcinoma was present in 16 (80\%) cases (Figures 3c-f and 4, see Tables 2-5). Most of the invasive adenocarcinomas showed, either focally or predominantly, a tubular pattern (Figure 3c), virtually indistinguishable from ordinary cholangiocarcinomas, composed of relatively small tubular units infiltrating into desmoplastic stroma. In $50 \%$ the predominant pattern was this conventional tubular pattern. In addition, $25 \%(4 / 16)$ of the invasive carcinomas displayed a distinctive pattern composed of large groups of cells with smooth contours, and as such, imitated the 'in-situ' component of the tumor (in situ-like invasive carcinoma) (Figure 3d, Tables 3-5). This pattern was often associated with comedonecrosis (Figures $3 \mathrm{~d}$ and 4a). The invasive nature of these components could be determined mostly by their sheer amount (7090\% invasive carcinoma, see Table 5) and infiltrative distribution (Figure 4). All cases were identified in an intrahepatic location and one patient presented with lymph-node metastasis at diagnosis (see details in Table 5). This pattern of invasive carcinoma is highly unusual and may be specific to intraductal tubulopapillary neoplasm.

Cytologically, the invasive carcinomas had a cytology characteristic of ordinary cholangiocarcinomas. Additionally $6 \%$ of invasive carcinomas had prominent clear cell features (Figure 3e).

Table 6 Mucin expression in intraductal tubulopapillary neoplasms

\begin{tabular}{|c|c|c|c|c|c|c|c|c|c|c|c|c|}
\hline \multirow[b]{3}{*}{ MUC1 } & \multicolumn{6}{|c|}{ Intraductal component } & \multicolumn{6}{|c|}{ Invasive component } \\
\hline & \multicolumn{2}{|c|}{ Overall positivity } & \multicolumn{2}{|c|}{ Focal } & \multicolumn{2}{|c|}{ Diffuse } & \multicolumn{2}{|c|}{ Overall positivity } & \multicolumn{2}{|c|}{ Focal } & \multicolumn{2}{|c|}{ Diffuse } \\
\hline & $16 / 20$ & $80 \%$ & $8 / 20$ & $40 \%$ & $8 / 20$ & $40 \%$ & $11 / 13$ & $85 \%$ & $5 / 13$ & $38 \%$ & $6 / 13$ & $46 \%$ \\
\hline MUC2 & $\mathbf{0} / 20$ & $0 \%$ & 0 & $0 \%$ & 0 & $0 \%$ & 0/13 & $0 \%$ & 0 & $0 \%$ & 0 & $0 \%$ \\
\hline MUC5AC & $\mathbf{0} / \mathbf{2 0}$ & $0 \%$ & 0 & $0 \%$ & 0 & $0 \%$ & $0 / 13$ & $0 \%$ & 0 & $0 \%$ & 0 & $0 \%$ \\
\hline MUC6 & $6 / 20$ & $30 \%$ & 0 & $0 \%$ & $6 / 20$ & $30 \%$ & $7 / 13$ & $54 \%$ & $1 / 13$ & $8 \%$ & $6 / 13$ & $46 \%$ \\
\hline CDX2 & $2 / 18$ & $11 \%$ & $2 / 18$ & $11 \%$ & 0 & $0 \%$ & $0 / 11$ & $0 \%$ & 0 & $0 \%$ & 0 & $0 \%$ \\
\hline
\end{tabular}

${ }^{\mathrm{a} E x c l u s i o n}$ criteria.

Bold text highlights overall positive cases including both focal and diffuse. 

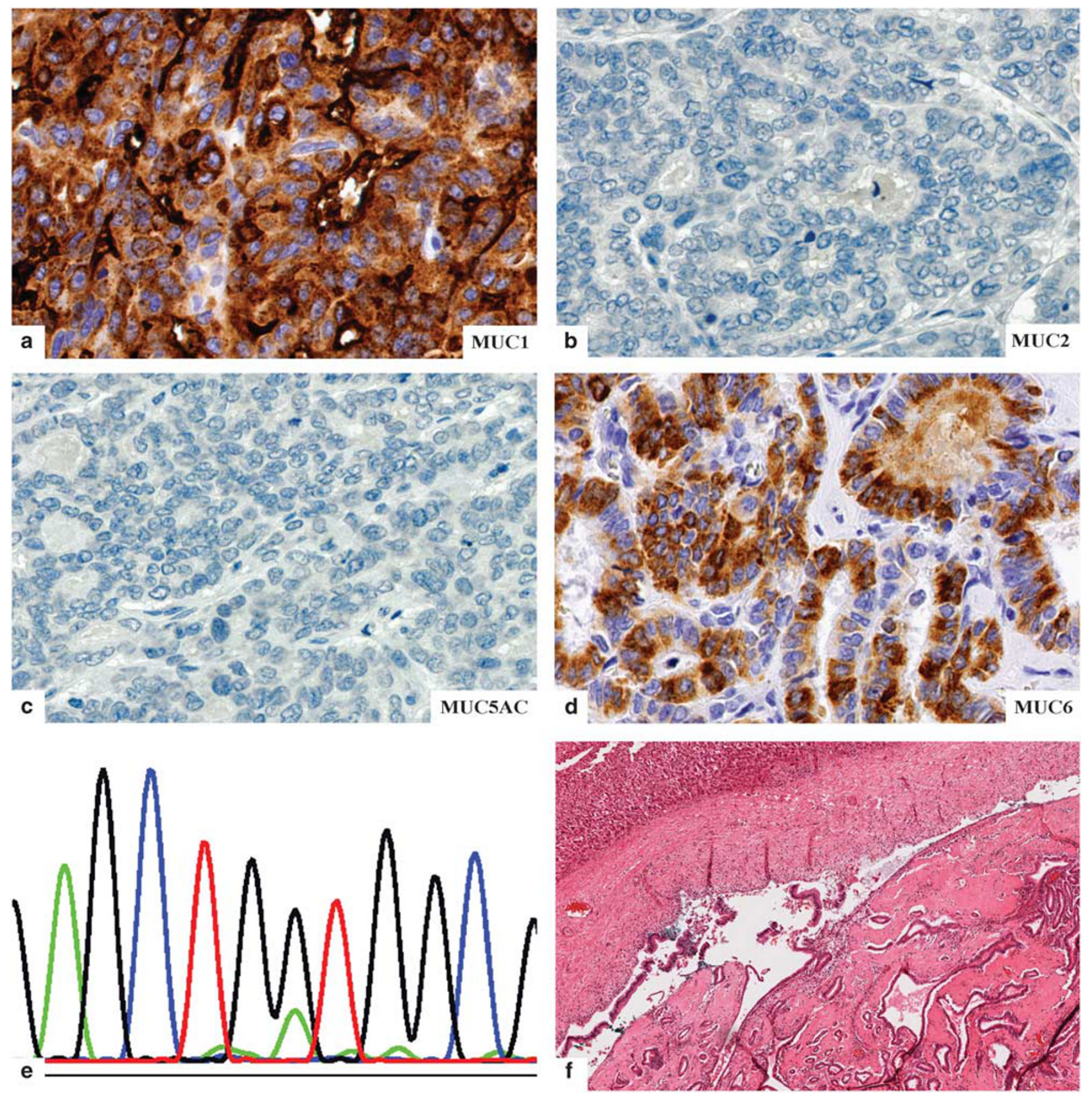

Figure 5 Immunohistochemical profile of biliary intraductal tubulopapillary neoplasms: (a) MUC1 (diffuse expression), (b) MUC2 (not expressed), (c) MUC5AC (not expressed; exclusion criteria), and (d) MUC6 (diffuse expression). Molecular findings: (e) mutated KRAS (exon 2, p.G12D) was identified in a single case with papilloma-like morphology (f).

In $13 \%$ of the cases, the invasive component was composed of large cystic units that formed a deceptively circumscribed lesion with sieve-like pattern (Figures $3 \mathrm{f}$ and $4 \mathrm{~b}$ ) characteristic of a distinctive type of invasive carcinoma of biliary tract that is recently proposed to be designated as tubulocystic carcinoma due to its striking similarity to the kidney cancer with the same name. ${ }^{35-37}$ An intraductal tubulopapillary neoplasm with similar tubulocystic features has also been observed in the pancreas. ${ }^{38}$ In the tubulocystic areas, the cysts were lined by attenuated and deceptively bland-appearing cells (Figure 4b) with densely chromophilic cytoplasm and the nuclei often had prominent nucleoli. In some of the cysts, abortive daughter niduses of tubular/tubulopapillary pattern could be observed (Figure 3f). This raised the question of whether these cysts represented secondary dilatations of the adjacent ducts; however, the distribution, cytology, and presence of perineural invasion by these seemingly bland cystic ducts confirmed their invasive nature.

The invasive component constituted 5-90\% of the tumor (mean: 52\%). Forty-four percent were graded as well-differentiated (G1), 50\% moderately 
differentiated (G2), and 6\% poorly differentiated (G3). In the recently proposed scheme of classification of cholangiocarcinomas by Liau et al, ${ }^{27} 9 / 16$ (56\%) cases were felt to qualify as 'cholangiolar,' $5 / 16$ (31\%) of cases were indeterminate, and two cases showed tubulocystic invasion (9\%). One of the cases classified as indeterminate had clear cell differentiation reminiscent of the bile duct type (Figure 3e), but besides this case, no convincing examples of 'bile duct type' cases could be identified. Briefly, the former is characterized by architecturally more complex (with interconnecting small tubules, cribriform patterns) and relatively basaloid cells with scant cytoplasm and bland-appearing nuclei (Figure 3c), whereas the latter is more of the pancreatobiliary type adenocarcinomas as described in the pancreas.

\section{Mucin Expression}

The expression of mucin core proteins (MUC1, 2, $5 \mathrm{AC}$ and 6) as well as expression of the intestinal

Table 7 Oncogenic pathways in intraductal tubulopapillary neoplasms

\begin{tabular}{lcccr}
\hline & Intraductal & $\%$ & Invasive & $\%$ \\
\hline$p 16$ & $7 / 16$ & 44 & $3 / 9$ & 33 \\
Loss of expression & $6 / 16$ & 38 & $3 / 9$ & 33 \\
LOH & $1 / 12$ & 8 & $0 / 8$ & 0 \\
TP53 & $3 / 18$ & 17 & $1 / 11$ & 9 \\
Focal & $3 / 18$ & 17 & $1 / 11$ & 9 \\
Diffuse & $0 / 18$ & 0 & $0 / 11$ & 0 \\
SMAD4 & $1 / 15$ & 7 & $0 / 10$ & 0 \\
PIK3CA & $1 / 17$ & 6 & $0 / 9$ & 0 \\
Exon 2 & $0 / 17$ & 0 & $0 / 9$ & 0 \\
Exon 9 & $1 / 17$ & 6 & $0 / 9$ & 0 \\
KRAS & $1 / 16$ & 6 & $0 / 9$ & 0 \\
Exon 2 & $1 / 16$ & 6 & $0 / 9$ & 0 \\
Exon 3 & $0 / 16$ & 0 & $0 / 9$ & 0 \\
IDH1 (Exon 4) & $0 / 17$ & 0 & $0 / 9$ & 0 \\
IDH2 (Exon 4) & $0 / 17$ & 0 & $0 / 9$ & 0 \\
BRAF (codon 600) & $0 / 17$ & 0 & $0 / 9$ & 0 \\
GNAS1 (Exon 8) & $0 / 15$ & 0 & $0 / 9$ & 0 \\
$\beta$-Catenin & $0 / 19$ & 0 & $0 / 12$ & 0 \\
HER2 & $0 / 20$ & 0 & $0 / 12$ & 0 \\
EGFR & $0 / 19$ & 0 & $0 / 13$ & 0 \\
& & & & \\
\hline
\end{tabular}

transcription factor CDX2 was investigated individually in non-invasive intraductal tumors and their associated invasive carcinomas (Table 6, Figures $5 \mathrm{a}-\mathrm{d}$ ). In detail, the expression of MUC1 was commonly observed $(80 \%$ of non-invasive tumors and $85 \%$ of invasive carcinomas). MUC6 was expressed at lower frequencies $30 \%$ of noninvasive tumors and $54 \%$ of invasive carcinomas), and the non-invasive components labeled diffusely in $6 / 20(30 \%)$ cases, as it may be seen in complexpyloric type of intracholecystic papillary tubular neoplasms. ${ }^{20}$ None of the cases expressed MUC2, the intestinal (goblet) type mucin, and MUC5AC (exclusion criteria). Focal nuclear expression of CDX2 was observed in two intraductal tumors (11\%).

\section{Oncogenic Pathways in Intraductal Tubulopapillary Neoplasms}

Common oncogenic pathways were analyzed individually in intraductal tumors and associated invasive carcinomas, if a sufficient quantity of invasive tumor cells was available for DNA extraction (11/16 invasive cases). These are summarized in Table 7 . Alterations and mutations in oncogenic pathways that are common in biliary tract and other cancers were rare in intraductal tubulopapillary neoplasms. Loss of CDKN2A/p16 expression and/or LOH of the $C D K N 2 A$ locus on chromosome 9p21 were observed in $44 \%$ of non-invasive intraductal tubulopapillary neoplasms (7/16; loss of expression: 6/16, LOH: $1 / 12$ ) and $33 \%$ of invasive carcinomas (3/9; $3 / 9$ loss of expression, 0/8 LOH). Abnormal focal nuclear overexpression of TP53 was observed in a few noninvasive intraductal tubulopapillary neoplasms $(3 / 18,17 \%)$ and one invasive carcinoma $(1 / 11,9 \%)$. Loss of SMAD4 expression was observed in a single non-invasive intraductal tubulopapillary neoplasm $(1 / 15,7 \%)$, but SMAD4 was retained in all of the invasive carcinomas. A low prevalence of mutations was observed in the PIK3CA gene in a known hotspot in a single intraductal tumor $(1 / 17,6 \%$ and absent in invasive carcinomas). In detail, common mutation E545K (exon 9) was present in a single non-invasive lesion but absent in the associated invasive

Table 8 Survival analyses of intraductal tubulopapillary neoplasms, intraductal papillary neoplasms of the bile duct and conventional cholangiocarcinomas

\begin{tabular}{lccc}
\hline & $\begin{array}{c}\text { Intraductal tubulopapillary } \\
\text { neoplasms }\end{array}$ & $\begin{array}{c}\text { Intraductal papillary } \\
\text { neoplasms of the bile duct }\end{array}$ & $\begin{array}{c}\text { Conventional } \\
\text { cholangiocarcinomas }\end{array}$ \\
\hline$N$ & $15(23.4 \%)$ & $33(51.6 \%)$ & $16(25.0 \%)$ \\
Survival & $100 \%$ & $100.0 \%$ & $81.3 \%$ \\
1 year & $90 \%$ & $86.3 \%$ & $72.2 \%$ \\
3 years & $90 \%$ & $64.7 \%$ & $54.2 \%$ \\
5 years & & & $0.1301^{\mathrm{a}}$ \\
\hline
\end{tabular}

Log-rank test intraductal tubulopapillary neoplasms vs intraductal papillary neoplasms of the bile duct: $P$-value $=0.2708$.

Log-rank test intraductal tubulopapillary neoplasms vs conventional cholangiocarcinomas: $P$-value $=0.0709$.

${ }^{\mathrm{a}}$ Log-rank test comparing all three groups.

${ }^{b}$ Wilcoxon test comparing all three groups-emphasizes differences between the beginning parts of the curves. 


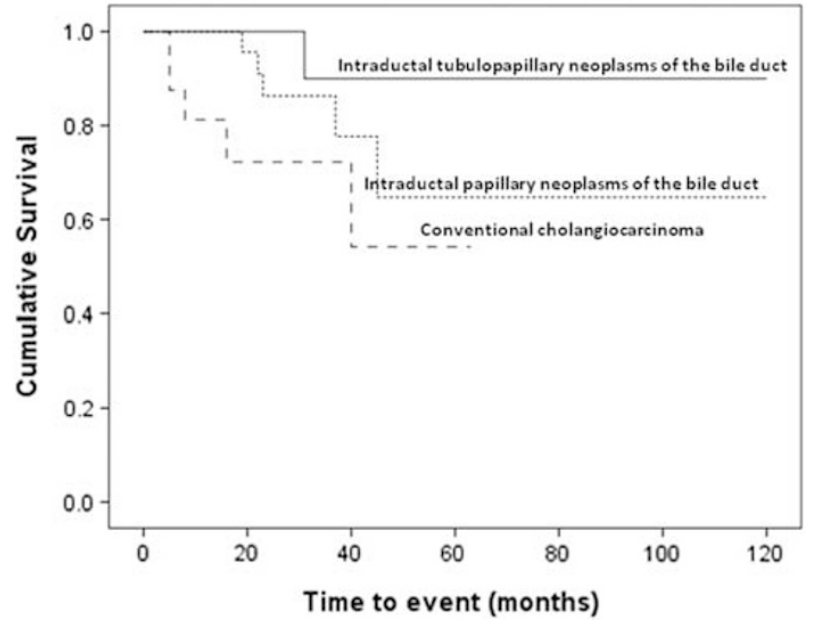

Figure 6 Kaplan-Meier survival curve comparing overall survival intraductal tubulopapillary neoplasms with intraductal papillary neoplasms of the bile duct and conventional cholangiocarcinoma patients (patients with perioperative mortality within the first 90 days after surgery were excluded from survival analysis): 3-year survival showed significant differences between the three groups (Wilcoxon test: $P=0.0474$ ).

carcinoma from the same case. Likewise mutated KRAS (G12D) (Figure 5e), which is very common in pancreatic intraductal neoplasms and pancreatic adenocarcinomas, was detected only in a single non-invasive intraductal tubulopapillary neoplasm $(6 \%)$, which proved to be a case with a distinct morphology showing prominent sclerosis resembling a sclerosing papilloma (Figure 5f). Otherwise, $K R A S$ was wild type in all invasive carcinomas. Wild-type BRAF (codon 600), GNAS (exon 8), IDH1 (exon 4), and IDH2 (exon4) were present in all noninvasive intraductal tubulopapillary neoplasms and all associated invasive carcinomas. Likewise, the overexpression of EGFR and HER2 and the aberrant nuclear expression of $\beta$-catenin were not detected.

\section{Clinical Outcome}

Follow-up information was available for 17 patients $(85 \%)$ with a mean follow-up of 44 months (range 1150, see Tables 2,3, and 8); three patients died during the observation period. Perioperative death occurred in two patients $(2 / 17,12 \%), 18$ and 39 days after surgery. One patient (a female, age 75 years at diagnosis) died at 31 months post diagnosis. The initial histological examination of the resection specimen in this case revealed intraductal tubulopapillary neoplasm in the extra-hepatic bile duct with high-grade dysplasia but no definite invasion despite substantial sampling (seven blocks). Interestingly, histological and molecular analyses revealed loss of SMAD4 (the only case of the cohort; 1/17), focal nuclear TP53 overexpression (one of three such cases in the cohort; $3 / 18$ ), and extensive necrosis as potential indicators of malignant behavior. At last appointment, the patient presented with clinically metastatic disease and hypertensive symptoms. Imaging revealed intrapulmonary nodules, multiple periportal and mesenteric lymph nodes, and a soft tissue mass surrounding the common bile duct.

Overall combined survival rates showed favorable prognosis, with 1-year survival $100 \%$, 3-year survival $90 \%$, and 5 -year survival $90 \%$ (Tables 2 and 8 , Figure 6). Survival data were compared with survival data of a previously published intraductal papillary neoplasm of the bile duct cohort and patients with conventional cholangiocarcinoma. ${ }^{9}$ Comparison of the survival rates showed significant differences between the three groups $(P=0.0474)$ (Table 8, Figure 6).

\section{Discussion}

It is now widely agreed upon that neoplasms characterized by a mass-forming preinvasive component (tumoral intraepithelial neoplasms), which can progress to invasive carcinoma, should be recognized separately from the ordinary carcinomas that arise from microscopic precursors because they are distinct biologically, prognostically, and at molecular levels. Furthermore, these neoplasms constitute an interesting model to study the carcinogenesis.

Recently, attention has been drawn to intraductal precursor lesions of the bile duct $^{4}$ and their similarities to their pancreatic counterparts., ${ }^{3,5}$ Biliary intraepithelial neoplasia and intraductal papillary neoplasms of the bile ducts are established as the dichotomous precursor lesions in the bile duct system $^{2,7,9,23}$ similar to pancreatic intraepithelial neoplasia and intraductal papillary mucinous neoplasms in the pancreas. ${ }^{29,39,40} \mathrm{~A}$ separate category of intraductal neoplasm (tumoral intraepithelial neoplasm) that is similar to, but also distinct from intraductal papillary mucinous neoplasms, is now recognized in the pancreas as intraductal tubulopapillary neoplasm of the pancreas, and the same tumor type is beginning to be appreciated in the bile duct system. ${ }^{18,19}$ However, many of the characteristics of biliary intraductal tubulopapillary neoplasms, and how they differ and relate to pancreatic intraductal tubulopapillary neoplasms or biliary intraductal papillary neoplasms of the bile duct have not yet been elucidated.

The goal of the present study was to investigate a large cohort of intraductal tubulopapillary neoplasms of the bile ducts with focus on their clinicopathologic characteristics as well as the molecular changes that drive carcinogenesis toward invasive carcinomas. Cases for this study were identified by the criteria put forth in the pancreas. Although the name of the entity includes 'papillary', in the pancreas, the entity of intraductal tubulopapillary neoplasm is mostly defined by almostexclusive tubular growth. ${ }^{16,41}$ A similar approach was taken in this study for biliary intraductal tubulopapillary neoplasms as well. In all 20 of the 

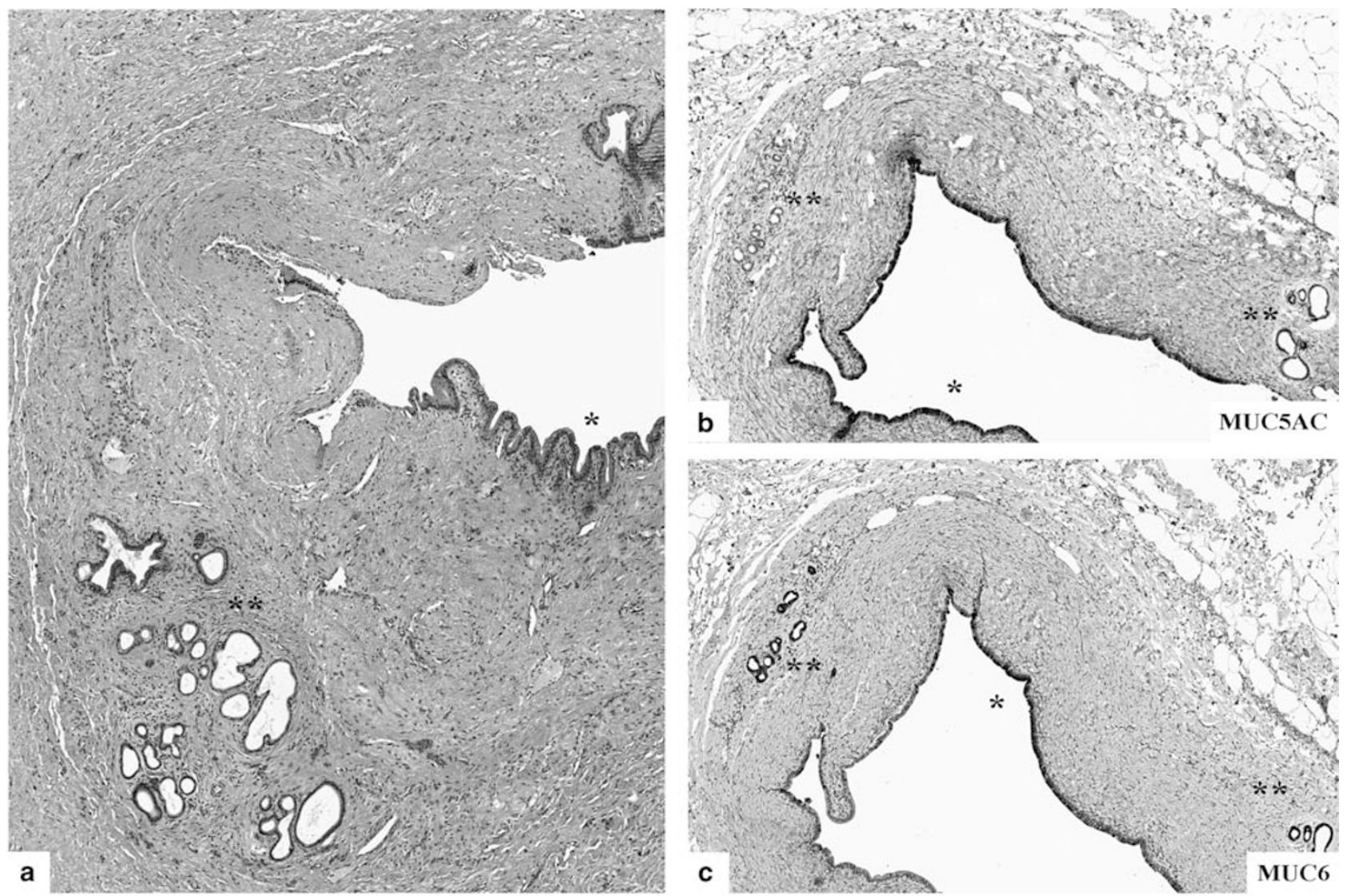

Putative cell of origin
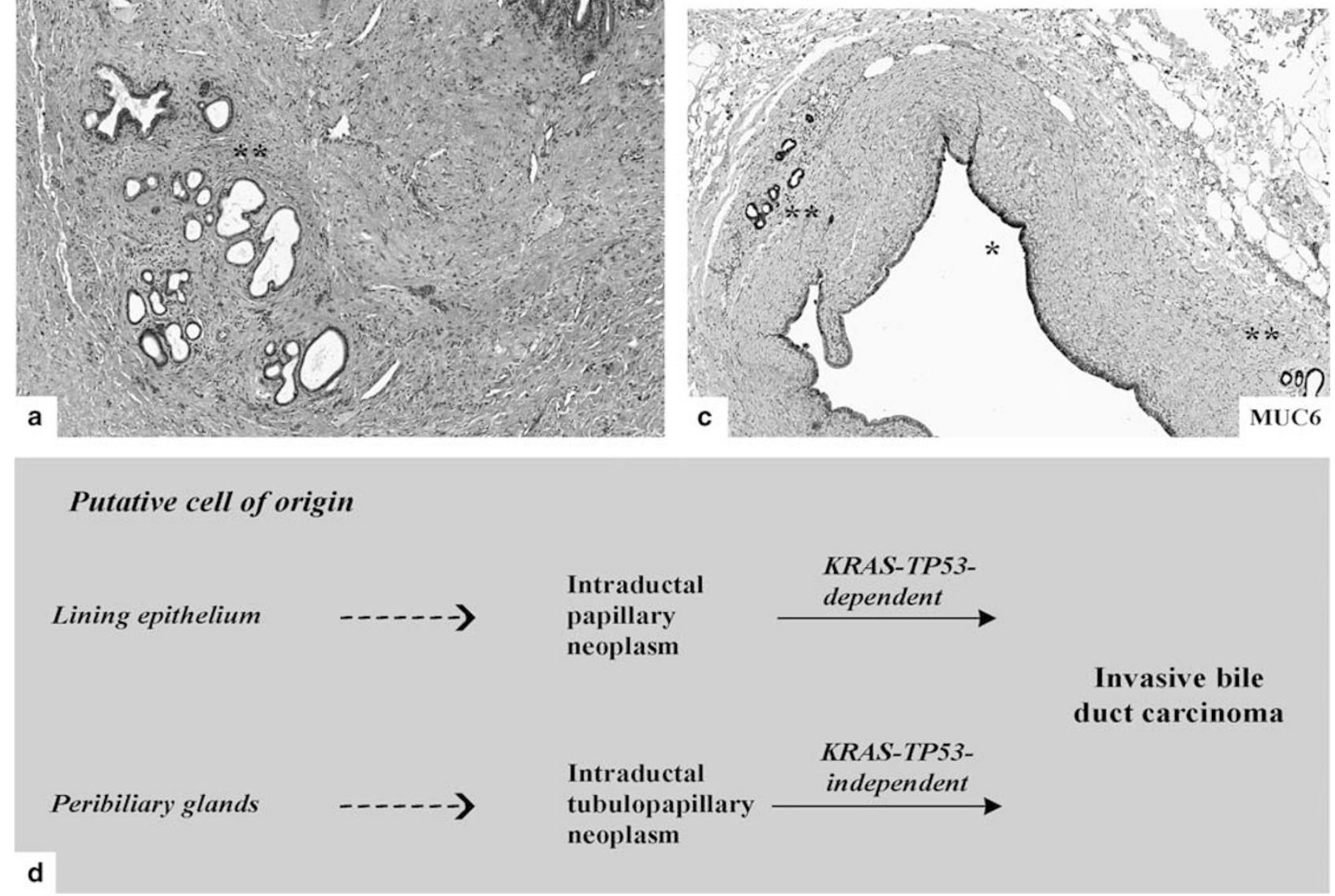

Figure 7 Speculations on origin of intraductal tubulopapillary neoplasms: (a) Morphology of normal bile duct with lining epithelium (*) and peribiliary glands $\left({ }^{* *}\right)$. (b) MUC2 is expressed in the lining epithelium $\left({ }^{*}\right)$ but absent in peribiliary glands (**). (c) MUC6 is expressed in lining epithelium $(*)$ and peribiliary glands $(* *)$. (d) Proposed model of intraductal tubulopapillary neoplasm and intraductal papillary neoplasm of the bile duct carcinogenesis.

cases included in this study, the papilla formation was often very limited, abortive, or virtually nonexistent, in accordance with the approach taken by Katabi and Klimstra who reported their 9 biliary cases under the heading of 'intraductal tubular neoplasms, ${ }^{19}$ Additionally, we have also carefully excluded the cases with more conventional pyloric gland pattern from our study. Figure 2 in the Katabi study gives the impression that such cases may have been included in their study, but the conversation with the authors (personal communication, David Klimstra, 2013) reveals that this may have been an aberration, and that that illustration exemplifies an unusual focus, and that the cases with prominent cytoplasmic mucin and pyloric gland features had been excluded from their study as well. Moreover, in our study, we not only excluded pyloric gland lesions by morphology, but also employed MUC5AC expression as an exclusion criterion, as proposed in the paper by Zen et $a 1^{18}$ in their analysis of two 
similar cases. We also excluded intraductal tubulopapillary neoplasm-like tumors of the gallbladder that are increasingly being recognized as a distinct subset of tumoral intraepithelial neoplasms of the gallbladder. ${ }^{20,21}$

Defined by these criteria, our study of 20 biliary intraductal tubulopapillary neoplasms does indeed outline that intraductal tubulopapillary neoplasms represent a discrete entity from both intraductal papillary neoplasms of the bile duct and ordinary cholangiocarcinoma with distinct morphology, immunohistochemical expression profile, molecular carcinogenesis, and tumor biology.

\section{Clinicopathologic Characteristics}

Similar to other tumoral intraepithelial neoplasms in the biliary tract, and also similar to cholangiocarcinomas, biliary intraductal tubulopapillary neoplasms are uncommon in the younger population, and are typically seen in mean age of 60s. There does not seem to be any striking gender predominance. The tumors can be large, measuring up to $15 \mathrm{~cm}(6.9 \mathrm{~cm})$. They are predominantly intrahepatic but can be seen in the extrahepatic bile ducts as well.

Histologically, our study revealed that, in addition to their intraductal growth, tubular pattern, and nonmucinous cell composition, intraductal tubulopapillary neoplasms also show various other characteristic morphologic features such as the occurrence of a solid and comedocarcinoma-like pattern. In addition, some cases exhibit tubulocystic carcinomas ${ }^{38}$ morphologically similar to tubulocystic carcinomas of the kidneys. ${ }^{37}$

\section{Invasive Carcinomas Associated with Intraductal Tubulopapillary Neoplasms}

Most of the biliary intraductal tubulopapillary neoplasms in our study were associated with invasive carcinomas $(80 \%)$. In addition to the more common conventional tubular invasive carcinomas, we less frequently encountered subtle and unusual forms of invasive carcinoma that need to be recognized by pathologists. Some invasive carcinomas arising in intraductal tubulopapillary neoplasms infiltrate the liver as large, round nodular components. As these nodules mimicked intraductal tissue growth, we termed these tumors invasive carcinoma with in situ-like pattern. The nodular invasive carcinomas also often had comedonecrosis. As recognized by Katabi et al, ${ }^{19}$ the diagnosis of invasive growth and the distinction between non-invasive and invasive tumors can be a major challenge in biliary intraductal tubulopapillary neoplasms, particularly for cases that present with this pushing border-like growth and cases with nodular growth of intraductal as well as invasive areas. Low-power examination illustrating the abnormal distribution of these units is crucial for accurate diagnosis. Fundamentally, this in situ-like invasive carcinoma is akin to the 'blunt' or 'pushingborder' type invasive carcinomas seen in other organs such as the breast (exemplified best in solid-papillary carcinoma $^{42-45}$ ) and more recently, even in the colon. ${ }^{46}$

Another problematic type of invasive carcinoma seen in intraductal tubulopapillary neoplasms is tubulocystic, ${ }^{37}$ which is characterized by conglomerates of cyst-forming ducts lined by attenuated cells giving the impression of a benign lesion. Upon close inspection, the cytologic atypia in the lining cells, including the prominent nucleoli, is often readily evident in these otherwise deceptively bland-appearing invasive carcinomas. Some also exhibit perineural invasion confirming their malignant nature.

\section{Molecular/Immunohistochemical Features}

The immunohistochemical mucin expression profile of intraductal tumors is a helpful tool to distinguish these distinct entities, both in the pancreas and in the bile duct system. ${ }^{7,9,10}$ Our data show that biliary intraductal tubulopapillary neoplasms exhibit a pancreatobiliary epithelial phenotype with MUC1 $(\sim 80 \%)$ and MUC6 $(\sim 30 \%)$ expression and negativity for MUC2 and particularly MUC5AC. The lack of MUC5AC expression is a key differentiator to biliary intraductal papillary neoplasms of the bile duct that commonly express MUC5AC $\left(78 \%{ }^{9}\right)$.

The molecular changes that drive the development of intraductal tubulopapillary neoplasms and their progression to invasive carcinomas are largely unknown. Our study shows that alterations of oncogenic signaling pathways, except CDKN2A/ $p 16$, that is commonly mutated in biliary intraductal papillary neoplasms of the bile duct and conventional cholangiocarcinomas ${ }^{9,47,48}$ are extremely rare in intraductal tubulopapillary neoplasms. The PIK3CA mutation rate is of special interest because it is a potential therapeutic target for inhibition of the PIK3CA/Akt pathway. ${ }^{47,49}$ Given the very low number of PIK3CA mutations in our study $6 \%$ in intraductal tubulopapillary neoplasms and absent in invasive carcinomas), the clinical potential seems to be limited in intraductal tubulopapillary neoplasms. Nuclear accumulation of TP53 was identified in few intraductal tubulopapillary neoplasms. Given the high frequency of alterations of the TP53 gene in conventional cholangiocarcinoma $(64 \%)^{9}$ and biliary intraductal papillary neoplasms $(67 \%),{ }^{9}$ the low frequency of alterations of the TP53 gene in noninvasive intraductal tubulopapillary neoplasms $(17 \%)$ and in associated invasive carcinoma (9\%) further highlights the fact that intraductal tubulopapillary neoplasms are indeed a separate entity among biliary carcinomas, driven by a distinct molecular pathogenesis. Similarly, the KRAS oncogene, another driver oncogene that is found in biliary intraductal papillary neoplasm $(36 \%)^{9}$ and in conventional cholangiocarcinomas $(14 \%)^{9}$, was 
identified in only a single case (6\%). Moreover, this particular case had a distinct morphology resembling sclerosing papilloma (Figure 5f), different from the rest of the group, although it overall fulfilled diagnostic criteria of intraductal tubulopapillary neoplasm. This finding shows that mutated KRAS is an exception in biliary intraductal tubulopapillary neoplasms, as reported by others ${ }^{18,19}$ and may be restricted to intraductal tubulopapillary neoplasm cases with hybrid morphology.

IDH1 and 2 mutations, recently shown to be among the most frequent mutations in intrahepatic cholangiocarcinomas, ${ }^{48,50}$ were absent in intraductal tubulopapillary neoplasms. Likewise, loss of SMAD4 was restricted to a single example. In addition, no mutations and no alterations were detected in EGFR, HER2, and BRAF. Taken together with our previously published study of the molecular carcinogenesis of biliary intraductal papillary neoplasms, ${ }^{9}$ our data point to a dual model for the carcinogenesis of intraductal biliary tumors: KRAS-TP53-dependent carcinogenesis of intraductal papillary neoplasms of the bile duct and KRAS-(TP53)-independent carcinogenesis of intraductal tubulopapillary neoplasms (Figure 7). Further studies using whole-exome sequencing and next-generation sequencing to discover yet unknown molecular changes are required to understand the carcinogenesis of intraductal papillary neoplasms of the bile duct and intraductal tubulopapillary neoplasms.

\section{Clinical Behavior}

Our data show that biliary intraductal tubulopapillary neoplasms have striking similarities to their pancreatic counterpart, morphologically, immunophenotypically, as well as at the molecular level. Not surprisingly, there are also striking parallels in their behavior as well. Both biliary and pancreatic intraductal tubulopapillary neoplasms exhibit a favorable prognosis, and this is despite the relatively high incidence of invasive carcinoma $(80 \%)$ that we saw in biliary intraductal tubulopapillary neoplasms. Whether this is a reflection of early discovery of the invasive carcinomas that are brought to attention by the large preinvasive component of intraductal tubulopapillary neoplasms or whether it is due to different molecular pathways that render a more indolent behavior to the invasive carcinomas arising from them is difficult to determine. Both our findings of peculiar invasive carcinoma patterns and our molecular findings seem to indicate that the latter possibility is in play. Along these lines, it may be also interesting to note that even the ordinary invasive adenocarcinomas arising from intraductal tubulopapillary neoplasms are more of the 'cholangiolar' rather than 'bile duct' type in the Liau classification, ${ }^{27}$ which were reported to be less aggressive. This may also be a factor in the more indolent behavior of intraductal tubulopapillary neoplasms-associated invasive carcinomas.

\section{Differences from Intraductal Papillary Neoplasms of the Bile Duct}

Morphologically, intraductal tubulopapillary neoplasms differ from intraductal papillary neoplasms of the bile duct ${ }^{9}$ by their characteristically tubular architecture and abortive papilla formation. Limited data show that intraductal tubulopapillary neoplasms are mostly intrahepatic $(70 \%)$ in contrast to intraductal papillary neoplasms of the bile duct that are more common in the extrahepatic bile duct. ${ }^{9}$ Although both entities have a similarly high incidence of invasive carcinoma $(80 \%$ of intraductal tubulopapillary neoplasms, $73 \%$ of intraductal papillary neoplasms of the bile duct), intraductal tubulopapillary neoplasms seem to show less aggressive biological behavior than intraductal papillary neoplasms of the bile duct (Figure 6, Table 8). Of special interest is the differential immunoprofile of these entities. They share, to some degree, both MUC1 (intraductal tubulopapillary neoplasms $80 \%$, intraductal papillary neoplasms of the bile duct $60 \%$ ) and MUC6 (intraductal tubulopapillary neoplasms $30 \%$, intraductal papillary neoplasms of the bile duct $33 \%$ ) expression. However, MUC5AC, which is commonly expressed in intraductal papillary neoplasms of the bile duct $(78 \%)$, is, as an exclusion criterion, absent in intraductal tubulopapillary neoplasms. Another exclusion criterion is the general lack of KRAS mutations and the low rate of TP53 overexpression, which are relatively common in intraductal papillary neoplasms of the bile duct. Taken together, the immunophenotypic and molecular differences between biliary intraductal tubulopapillary neoplasms and intraductal papillary neoplasms of the bile duct are so striking that they suggest distinct pathways of carcinogenesis for these two neoplasms.

\section{Acknowledgments}

We would like to thank Rhonda Everett for her expertize in the organization and preparation of this manuscript and Susanne Plaschke for excellent technical assistance. This study was supported in part by a fund recruited and donated by the Ilke and Mirkan Aydin family, and by NIH Grant CA62924.

\section{Disclosure/conflict of interest}

The authors declare no conflict of interest.

\section{References}

1 Zabron A, Edwards RJ, Khan SA. The challenge of cholangiocarcinoma: dissecting the molecular 
mechanisms of an insidious cancer. Dis Model Mech 2013;6:281-292.

2 Albores-Saavedra J, Adsay NV, Crawford JM et al. Carcinoma of the gallbladder and extrahepatic bile duct, In: Bosman FT, Carneiro F, Hruban RH, Theise ND (eds) World Health Organization Classification of Tumors of the Digestive System 4th (edn). IARC: Lyon, 2010, pp 266-273.

3 Nakanuma Y. A novel approach to biliary tract pathology based on similarities to pancreatic counterparts: is the biliary tract an incomplete pancreas? Pathol Int 2010;60:419-429.

4 Kloppel G, Adsay V, Konukiewitz B et al. Precancerous lesions of the biliary tree. Best Pract Res Clin Gastroenterol 2013;27:285-297.

5 Nakanuma Y, Harada K, Sasaki M, Sato Y. Proposal of a new disease concept "biliary diseases with pancreatic counterparts". Anatomical and pathological bases. Histol Histopathol 2014;29:1-10.

6 Zen Y, Sasaki M, Fujii T et al. Different expression patterns of mucin core proteins and cytokeratins during intrahepatic cholangiocarcinogenesis from biliary intraepithelial neoplasia and intraductal papillary neoplasm of the bile duct-an immunohistochemical study of 110 cases of hepatolithiasis. J Hepatol 2006;44:350-358.

7 Nakanuma Y, Curado M-P, Franceschi S et al. Intrahepatic cholangiocarcinomaIn:Bosman FT, Carneiro F, Hruban RH, Theise ND(eds) World Health Organization Classification of Tumors of the Digestive System 4th (edn). IARC: Lyon, 2010, pp 217-224.

8 Rocha FG, Lee H, Katabi N et al. Intraductal papillary neoplasm of the bile duct: A biliary equivalent to intraductal papillary mucinous neoplasm of the pancreas? Hepatology 2012;56:1352-1360.

9 Schlitter AM, Born D, Bettstetter M et al. Intraductal papillary neoplasms of the bile duct: stepwise progression to carcinoma involves common molecular pathways. Mod Pathol 2014;27:73-86.

10 Adsay NV, Fukushima N, Furukawa T et al. Intraductal neoplasms of the pancreasIn:Bosman FT, Carneiro F, Hruban RH, Theise ND (eds) World Health Organization Classification of Tumors of the Digestive System 4th (edn). IARC: Lyon, 2010, pp 304-313.

11 Esposito I, Bauer A, Hoheisel JD et al. Microcystic tubulopapillary carcinoma of the pancreas: a new tumor entity? Virchows Arch 2004;444:447-453.

12 Kloppel G, Basturk O, Schlitter AM, Konukiewitz B, Esposito I. Intraductal neoplasms of the pancreas. Semin Diagn Pathol 2014;31:452-466.

13 Amato E, Molin MD, Mafficini A et al. Targeted nextgeneration sequencing of cancer genes dissects the molecular profiles of intraductal papillary neoplasms of the pancreas. J Pathol 2014;233:217-227.

14 Yamaguchi $\mathrm{H}$, Kuboki Y, Hatori $\mathrm{T}$ et al. Somatic mutations in PIK3CA and activation of AKT in intraductal tubulopapillary neoplasms of the pancreas. Am J Surg Pathol 2011;35:1812-1817.

15 Yamaguchi H, Kuboki Y, Hatori T et al. The discrete nature and distinguishing molecular features of pancreatic intraductal tubulopapillary neoplasms and intraductal papillary mucinous neoplasms of the gastric type, pyloric gland variant. J Pathol 2013;231: 335-341.

16 Bhanot U, Basturk O, Berger $\mathrm{M}$ et al. Molecular characteristics of the pancreatic intraductal tubulopapillary neoplasm (Abstract). Mod Pathol 2015; 28:1761A.
17 Park HJ, Jang KT, Heo JS et al. A potential case of intraductal tubulopapillary neoplasms of the bile duct. Pathol Int 2010;60:630-635.

18 Zen Y, Amarapurkar AD, Portmann BC. Intraductal tubulopapillary neoplasm of the bile duct: potential origin from peribiliary cysts. Hum Pathol 2012; 43:440-445.

19 Katabi N, Torres J, Klimstra DS. Intraductal tubular neoplasms of the bile ducts. Am J Surg Pathol 2012;36: 1647-1655.

20 Adsay V, Jang KT, Roa JC et al. Intracholecystic papillary-tubular neoplasms (ICPN) of the gallbladder (neoplastic polyps, adenomas, and papillary neoplasms that are $>/=1.0 \mathrm{~cm}$ ): clinicopathologic and immunohistochemical analysis of 123 cases. Am J Surg Pathol 2012;36:1279-1301.

21 Balci S, Bagci P, Dursun N et al. Complex tubular type intracholecystic papillary tubular neoplasms (ICPN): further clinicopathologic and molecular characterization (Abstract). Mod Pathol 2014;27:446A.

22 Zen Y, Pedica F, Patcha VR et al. Mucinous cystic neoplasms of the liver: a clinicopathological study and comparison with intraductal papillary neoplasms of the bile duct. Mod Pathol 2011;24:1079-1089.

23 Zen Y, Adsay NV, Bardadin K et al. Biliary intraepithelial neoplasia: an international interobserver agreement study and proposal for diagnostic criteria. Mod Pathol 2007;20:701-709.

24 Ohike N, Kim GE, Tajiri $\mathrm{T}$ et al. Intra-ampullary papillary-tubular neoplasm (IAPN): characterization of tumoral intraepithelial neoplasia occurring within the ampulla: a clinicopathologic analysis of 82 cases. Am J Surg Pathol 2010;34:1731-1748.

25 Mayo SC, Shore AD, Nathan $\mathrm{H}$ et al. Refining the definition of perioperative mortality following hepatectomy using death within 90 days as the standard criterion. HPB (Oxford) 2011;13:473-482.

26 Elston CW, Ellis IO. Pathological prognostic factors in breast cancer. I. The value of histological grade in breast cancer: experience from a large study with longterm follow-up. Histopathology 1991;19:403-410.

27 Liau JY, Tsai JH, Yuan RH et al. Morphological subclassification of intrahepatic cholangiocarcinoma: etiological, clinicopathological, and molecular features. Mod Pathol 2014;27:1163-1173.

28 Basturk O, Khayyata S, Klimstra DS et al. Preferential expression of MUC6 in oncocytic and pancreatobiliary types of intraductal papillary neoplasms highlights a pyloropancreatic pathway, distinct from the intestinal pathway, in pancreatic carcinogenesis. Am J Surg Pathol 2010;34:364-370.

29 Adsay NV, Merati K, Andea A et al. The dichotomy in the preinvasive neoplasia to invasive carcinoma sequence in the pancreas: differential expression of MUC1 and MUC2 supports the existence of two separate pathways of carcinogenesis. Mod Pathol 2002;15:1087-1095.

30 Luttges J, Zamboni G, Longnecker D, Kloppel G. The immunohistochemical mucin expression pattern distinguishes different types of intraductal papillary mucinous neoplasms of the pancreas and determines their relationship to mucinous noncystic carcinoma and ductal adenocarcinoma. Am J Surg Pathol 2001;25: 942-948.

31 Bettstetter M, Berezowska S, Keller G et al. Epidermal growth factor receptor, phosphatidylinositol-3-kinase catalytic subunit/PTEN, and KRAS/NRAS/BRAF in 
primary resected esophageal adenocarcinomas: loss of PTEN is associated with worse clinical outcome. Hum Pathol 2013;44:829-836.

32 Tefferi A, Lasho TL, Abdel-Wahab O et al. IDH1 and IDH2 mutation studies in 1473 patients with chronic-, fibrotic- or blast-phase essential thrombocythemia, polycythemia vera or myelofibrosis. Leukemia 2010;24: 1302-1309.

33 Trkova M, Babjuk M, Duskova J et al. Analysis of genetic events in 17 p13 and 9p21 regions supports predominant monoclonal origin of multifocal and recurrent bladder cancer. Cancer Lett 2006;242:68-76.

34 Unger P, Perino G, Schiff H et al. Eosinophilic globules resembling Mallory bodies in a renal cell carcinoma. $\mathrm{N}$ Y State J Med 1992;92:18-20.

35 Amin MB, MacLennan GT, Gupta R et al. Tubulocystic carcinoma of the kidney: clinicopathologic analysis of 31 cases of a distinctive rare subtype of renal cell carcinoma. Am J Surg Pathol 2009;33:384-392.

36 Yang XJ, Zhou M, Hes O et al. Tubulocystic carcinoma of the kidney: clinicopathologic and molecular characterization. Am J Surg Pathol 2008;32:177-187.

37 Jang KT, Saka B, Zen Y et al. Tubulocystic carcinoma of bile ducts: a hitherto unrecognized and diagnostically challenging entity often mistaken as a benign lesion; clinicopathologic analysis of 6 cases (Abstract). Mod Pathol 2013;26:404A.

38 Konigsrainer I, Glatzle J, Kloppel G, Konigsrainer A, Wehrmann M. Intraductal and cystic tubulopapillary adenocarcinoma of the pancreas-a possible variant of intraductal tubular carcinoma. Pancreas 2008;36: 92-95.

39 Hruban RH, Adsay NV, Albores-Saavedra J et al. Pancreatic intraepithelial neoplasia: a new nomenclature and classification system for pancreatic duct lesions. Am J Surg Pathol 2001;25:579-586.

40 Hruban RH, Takaori K, Klimstra DS et al. An illustrated consensus on the classification of pancreatic intraepithelial neoplasia and intraductal papillary mucinous neoplasms. Am J Surg Pathol 2004;28: 977-987.
41 Klimstra DS, Adsay NV, Dhall D et al. Intraductal tubular carcinoma of the pancreas: clinicopathologic and immunohistochemical analysis of 18 cases (Abstract). Mod Pathol 2007;20:285A.

42 Rakha EA, Gandhi N, Climent F et al. Encapsulated papillary carcinoma of the breast: an invasive tumor with excellent prognosis. Am J Surg Pathol 2011;35: 1093-1103.

43 Nassar H, Qureshi H, Adsay NV, Visscher D. Clinicopathologic analysis of solid papillary carcinoma of the breast and associated invasive carcinomas. Am J Surg Pathol 2006;30:501-507.

44 Collins LC, Carlo VP, Hwang $\mathrm{H}$ et al. Intracystic papillary carcinomas of the breast: a reevaluation using a panel of myoepithelial cell markers. Am J Surg Pathol 2006;30:1002-1007.

45 Wynveen CA, Nehhozina T, Akram M et al. Intracystic papillary carcinoma of the breast: an in situ or invasive tumor? Results of immunohistochemical analysis and clinical follow-up. Am J Surg Pathol 2011;35:1-14.

46 Gonzalez RS, Cates JMM, Washington MK et al. Adenoma-like adenocarcinoma: a subtype of colorectal carcinoma with good prognosis, deceptive appearance on biopsy, and frequent KRAS mutation. Histopathology; advance online publication, 24 April 2015; doi:10.1111/his.12725 (e-pub ahead of print).

47 Noel MS, Hezel AF. New and emerging treatment options for biliary tract cancer. Onco Targets Ther 2013;6:1545-1552.

48 Borger DR, Tanabe KK, Fan KC et al. Frequent mutation of isocitrate dehydrogenase (IDH)1 and IDH2 in cholangiocarcinoma identified through broad-based tumor genotyping. Oncologist 2012;17:72-79.

49 Voss JS, Holtegaard LM, Kerr SE et al. Molecular profiling of cholangiocarcinoma shows potential for targeted therapy treatment decisions. Hum Pathol 2013;44:1216-1222.

50 Wang $\mathrm{P}$, Dong Q, Zhang $\mathrm{C}$ et al. Mutations in isocitrate dehydrogenase 1 and 2 occur frequently in intrahepatic cholangiocarcinomas and share hypermethylation targets with glioblastomas. Oncogene 2013;32:3091-3100. 